\title{
Impact of Solvolysis Process on Both Depolymerization Kinetics of Nylon 6 and Recycling Carbon Fibers from Waste Composite
}

\author{
C. Chaabani ${ }^{1} \cdot$ E. Weiss-Hortala ${ }^{1} \cdot$ Y. Soudais ${ }^{1}$
}

\begin{abstract}
Carbon fibers reinforced polymers (CFRP) are extensively used. Regarding the high cost of production, the carbon fibers reuse is an important challenge. Chemical recycling using sub and supercritical fluids shows good prospects for recycling carbon fibers. Thus, solvolysis of CFRP waste was investigated to determine suitable operating conditions for preserving mechanical properties of carbon fibers, and to evaluate the kinetics parameters as well as the main reaction scheme. The experiments of decomposition of nylon 6 were carried out at temperatures in subcritical $\left(280-350^{\circ} \mathrm{C}\right)$ and in supercritical $\left(400-600^{\circ} \mathrm{C}\right)$ regions under the estimated pressure of $25 \mathrm{MPa}$ for reaction times of 1-120 min. The microstructure of the recovered carbon fibers was observed using environmental scanning electron microscopy (ESEM) and Raman spectroscopy. The amount of carbon, measured by Total organic carbon (TOC), in the liquid phase highlights that the depolymerization was enhanced compared to a complete degradation into $\mathrm{CO}_{2}$. In subcritical region, the resin removal reached $98.95 \mathrm{wt} \%$ at $280^{\circ} \mathrm{C}$ in $30 \mathrm{~min}$ while, in supercritical region, it has already reached $97.18 \mathrm{wt} \%$ at $400^{\circ} \mathrm{C}$ in only $15 \mathrm{~min}$. The monomer of the resin and other molecules were identified by gas chromatography coupled to mass spectroscopy (GC-MS) in liquid phases recovered from both regions. Assuming a pseudo-first order reaction, the activation energy was evaluated to be 77.79 and $78.51 \mathrm{~kJ} /$ mol in the subcritical and supercritical regions respectively. These kinetics parameters highlight that the reaction mechanism pathways are similar in both regions. ESEM
\end{abstract}

Y. Soudais

yannick.soudais@mines-albi.fr

1 Université de Toulouse, Ecole des Mines d'Albi, CNRS, RAPSODEE, Albi, France results revealed clean carbon fibers. The tensile strength of recovered carbon fibers was close to that of virgin fibers. However, Weibull moduli of recovered carbon fibers showed a large distribution of defects which was confirmed by Raman analysis that displayed a slight modification in carbon structure.

Keywords Carbon fibers · Recycling - Thermoplastic resin $\cdot$ Supercritical water

\section{Introduction}

Regardless their good resistance and high rigidity, composite materials present the advantage of being lightweight, compared to steel and aluminium. Thus, they are employed in many industrial fields such as automotive, aeronautics and sports. The worldwide demand for composites reached approximately 59,000 tons in 2011 and expected to be 208,000 tons by 2020 [1]. Especially, carbon fibers reinforced polymers (CFRP) materials have the largest share of the market (40\%), followed by glass fibers (31\%) [2]. With the extensive use area of CFRP, the global demand of carbon fibers is expected to rise from 46,000 tons in 2011 to 140,000 tons by 2020 [2]. Thus, the amount of carbon fibers based composite residues is going to increase. Since thermoplastics and thermosetting polymers are nonbiodegradable, nowadays, the main treatments are landfill and incineration. However, these two options contradict sustainable development. Thus, the European directives (1999/31/EC) and (2000/76/EC) have been adopted in order to minimize as much as possible the amount of waste destined to landfill and incineration. Therefore recycling options should be developed. 
The criterion of carbon fibers recycling is related to the preservation of the mechanical properties of the recovered fibers in order to be reused in a composite [2]. Currently, the recovery of carbon fibers from waste composites could be done through mechanical, pyrolysis, steam thermolysis or solvolysis processes. Mechanical process was first applied for composite residues reinforced thermosetting matrix glass fibers [3-5]. This method was then used to recycle carbon fiber from composites with thermoplastic or thermosetting resins [6,7]. This process allows the preservation of pieces of 4 to $15 \mathrm{~mm}$ of fibers. However the pieces of fibers are still impregnated with the polymer that limits the possibilities offered for recycling. Typical applications for these recyclates is the use in construction industry such us artificial woods. In France, this process is applied by Mixt Composites Recyclables. In the pyrolysis process, CFRP materials are pyrolysed in a reactor at $450-800^{\circ} \mathrm{C}$ in the absence of oxygen. The organic material from the polymer matrix is degraded and volatilised into lighter products: hydrogen, carbon dioxide, methane and other hydrocarbons. The recovered solid phase consists of fibers, with or without resin depending on operating conditions. However, pyrolysis process could result in char deposit, which should be oxidized. This post treatment could influence negatively the mechanical properties of recovered carbon fibers. The pyrolysis technique is already used by different companies worldwide such as ELG Carbon Fibre Ltd. In United Kingdom, MIT-RCF in the United States, CFK Valley Stade Recycling GmbH \& Co. KG in Germany and Karborek Recycling Carbon fibers in Italy. Recovered products by pyrolysis and mechanical process present low-value applications since mechanical performance are limited: mechanical treatment does not separate resin from fibers and pyrolysis should cope with charring issues (loss of tensile strength of recovered carbon fibers about $30 \%$ at $600^{\circ} \mathrm{C}$ [8]). Thus steam thermolysis and solvolysis were recently deeper investigated. On the one hand, steam thermolysis has shown two main advantages compared to pyrolysis process [9]: the resin elimination is improved using the same temperature conditions and the steam partially inhibits char deposit at the carbon fibers surface. On the other hand, solvolysis in supercritical fluids has shown good results to recover carbon fibers that can be reused [10]. In the solvolysis process, CFRP materials are processed in a reactor containing a suitable solvent at high temperature and/or pressure. Recently, Morin et al. [10] reviewed these methods for the recycling of carbon fibers reinforced polymers and concluded that chemical recycling is a favourable process to recover carbon fibers with good surface and mechanical properties. For this purpose, solvolysis of carbon fibers reinforced composites has been extensively investigated using batch or semi-continuous reactors in near- or supercritical conditions of water [11-13], in supercritical alcohols $[14,15]$ or in mixtures [15]. Since the recycling depends strongly on mechanical properties, it is important to evaluate the tensile strength of recovered carbon fibers. Okajima et al. [16] studied the recycling of CFRP in supercritical methanol, and clean carbon fibers were recovered at $380^{\circ} \mathrm{C}, 25 \mathrm{MPa}$. The tensile strength of the fibers was $9 \%$ less than virgin ones. Liu et al. [17] confirmed that solvolysis is efficient to recover carbon fibers with a tensile strength between 2 and $10 \%$. In addition, Pinero-Hernanz et al. [18] has investigated chemical recycling of CFRP using sub and supercritical alcohols. The process was able to depolymerize all the epoxy resin and produce fibers that retain $85-99 \%$ of the tensile strength of virgin carbon fibers. It has been shown that the use of alkali catalysts could decrease the tensile strength. Guozhan and Pickering [19] have shown that the effect of recycling process on recovered carbon fibers properties can be attributed to two factors: oxidative effect and thermal effect. In solvolysis process, only the thermal effect can be considered, while, in pyrolysis process followed by the char oxidation, both are involved. According to the properties of recycled carbon fibers from pyrolysis and solvolysis recycling, it can be concluded that the thermal effect does not induce impacts on mechanical properties. However, it results in a reduction in the ratio Oxygen/Carbon at fibers surface. Thus, the reduction in tensile strength may be attributed to oxidative effect.

Although the added value material is clearly the recovered carbon fiber, the authors are recently paying more attention to the resin removal, which may also provide interesting compounds (gaseous phase or useful organics). Ghaemy et al. [20] studied the decomposition of polyethylene terephthalate resin in ethylene glycol using metal acetate as a catalyst. They assumed a depolymerisation reaction since the glycolysis products mainly consisted of bis(hydroxyethyl) terephthalate (more than 75\%) in the liquid phase. Onwudili et al. [13] also reported the dissolving of up to $81 \mathrm{wt} \%$ of the epoxy resin in water in the presence of $\mathrm{NaOH}$ or $\mathrm{KOH}$ at short reaction time at $400^{\circ} \mathrm{C}$. Platform molecules such as phenol and aniline which represent a potential monomer recovery were significantly recovered. Moreover, the decomposition of polybenzoxazine resin in ethylene glycol/water revealed the presence of aniline, methylaniline, quinolone and phenyloxazine at $400{ }^{\circ} \mathrm{C}$ [21]. They were also interested in the degradation of this liquid phase into gaseous molecule by supercritical water gasification. The main products were $\mathrm{H}_{2}, \mathrm{CO}, \mathrm{CO}_{2}$, $\mathrm{CH}_{4}$ and $\mathrm{C}_{2} \mathrm{H}_{4}$. Thus, the decomposition of resin in nearcritical conditions is expected to be a depolymerisation reaction rather than a complete degradation. The decomposition reaction depends on operating conditions and on the chemical nature of resin. Oliveux et al. [22, 23] and Morin et al. [10] have reviewed the treatment of composites 
waste based on several thermoset and thermoplastic resins. Strong resins such as epoxydes could be decomposed in the range of temperature $370-460{ }^{\circ} \mathrm{C}$ within $15 \mathrm{~min}$ and needs even catalysts to be decomposed easily. However, most of thermoplastic can depolymerize easily except polyetheretherketone and polyphenylene sulphide which requires high temperature and strong acidic and alkaline conditions. Thermoplastic polyurethane and polybutylene terephthalate needs about $300-370^{\circ} \mathrm{C}$ to be decomposed. Among the thermoplastic polymers, Polyamides are of great interest as they are an important engineering plastic (high fatigue strength, resistance to chemical products...) widely used in different fields (automotive industry, fibers, clothing...). Their consumption is increasing year by year. Thus, recycling of waste polyamides by depolymerization (monomerization) becomes more urgent. Patil et al. [24] studied the depolymerization of nylon 6,6 using acid chloride. The yield of depolymerization was $72.20 \%$ for two hours of reaction time at $80^{\circ} \mathrm{C}$. While Kamimura et al. [25] were interested to the depolymerization of nylon-12 in supercritical Methanol in the presence of glycolic acid to $\omega$-hydroxyalcanoic acids. The glycolic acid was used to enhance the chemoselectivity towards producing acid function. Then, the decomposition reaction produced $85 \%$ of $\omega$-hydroxy-dodecanoate acid. In addition, depolymerization of PA6 sheets in sub and supercritical water [26, 27] and in supercritical alcohols [28, 29] has been well studied previously. Hydrolysis produces 6-aminocaproic acid and $\varepsilon$-caprolactam (monomer of PA6) in the liquid phase formed. Wang et al. [30] studied the hydrolysis of Monomer Casting nylon (MC nylon), which is a special kind of PA6, in subcritical water. They found that MC nylon decomposed completely within $45 \mathrm{~min}, 345^{\circ} \mathrm{C}$ and $9 \mathrm{MPa}$. The reaction of decomposition produces 6-aminocaproic acid as an intermediate product and proceeds to reach $89 \%$ of the goal product which is the monomer $\varepsilon$-caprolactam within $75 \mathrm{~min}$. However, alcoolysis generates aminocaproic ester as the major product which could be transformed into $\varepsilon$-caprolactam by further reaction (such as $N$-alkylation using methanol). Kamimura et al. [31] studied the conversion of polyamides especially PA6 into valuable chemical materials (hydroxycaproic acid derivatives) using supercritical methanol. According to their results, the reaction of decomposition of pure PA6 and waste PA6 produced the same reaction profile of these products: caprolactam, $\mathrm{N}$-Methylcaprolactam, methyl 6-( $N, N$-dimethylamino) capronate, methyl 6-hydroxycapronate, methyl 6-hexanoate and methyl 6-methoxycapronate. This means that solvolysis process using supercritical methanol was efficient to convert waste nylon- 6 . To our knowledge, no work has been already done on PA6 from CFRP. Therefore, recycling of carbon fibers composite based PA6 resin is investigated in this paper. In our previous work [32], the efficiency of different solvent (water, ethanol and acetone) was studied. Results showed that in a viewpoint of reactivity, water and ethanol were more efficient compared to acetone. However, water takes advantages in the ecological point of view and is the solvent selected for deeper investigations.

Our present study is focused on the solvolysis efficiency in order to reuse carbon fibers and to valorize the resin. Our aim is to study the mechanical, surface and structural properties of the recovered carbon fibers in order to support further optimisation of recycling processes in largescale operations. In addition, a better understanding of the reactions involved in the resin removal (depolymerisation, oxidation, charring effects) should help to understand both the mechanical properties of the recovered fibers and the resin valorization. Indeed, resin valorization may be done through energetic synthetic gas or with platform molecules recovery.

\section{Materials and Methods}

\section{Materials}

Cut-off Carbostamp UD Tape composites (Torayca T700SC M0E carbon fibers and PA6 resin) were used as the raw material. The size of the composite (length/ Width) is $35 \mathrm{~mm} / 5.5 \mathrm{~mm}$. PA6 resin represents $39-40 \%$ in the cutoff strips. Strips of composite are provided by Toray with a thickness of $0.28 \mathrm{~mm}$.

The amount of the resin in the composite was experimentally determined (TGA and normalized oxidation procedure: EN 2564:1998) and compared to the company data. The amount of resin is equal to $39.0 \mathrm{wt} \%$. The resin contains in majority organic materials. Minerals represent only $0.02 \mathrm{wt} \%$ of the mass of the resin. In addition, the amount of carbon was also evaluated (Total organic carbon using a solid module) in the resin and was about $78.1 \mathrm{wt} \%$. Both values are then used to provide efficiency parameters.

\section{Solvolysis Process}

Figure 1 shows the principle of the experimental setup to determine the optimum conditions to decompose the PA6 resin in sub and supercritical water.

The $5 \mathrm{~mL}$ batch reactor was composed of 316 stainless steel. A given weight of the composite (about $0.1 \mathrm{~g}$ ) was put in the reactor and then filled with ultrapure water. The volume of liquid calculated at room temperature depends on its density at the desired temperature and pressure. Thermodynamics properties were determined by Water\&Steam software (Springer). An oven (chromatographic or muffle oven Nabertherm) was preheated at the desired temperature $\left(280-350^{\circ} \mathrm{C}\right)$ or 


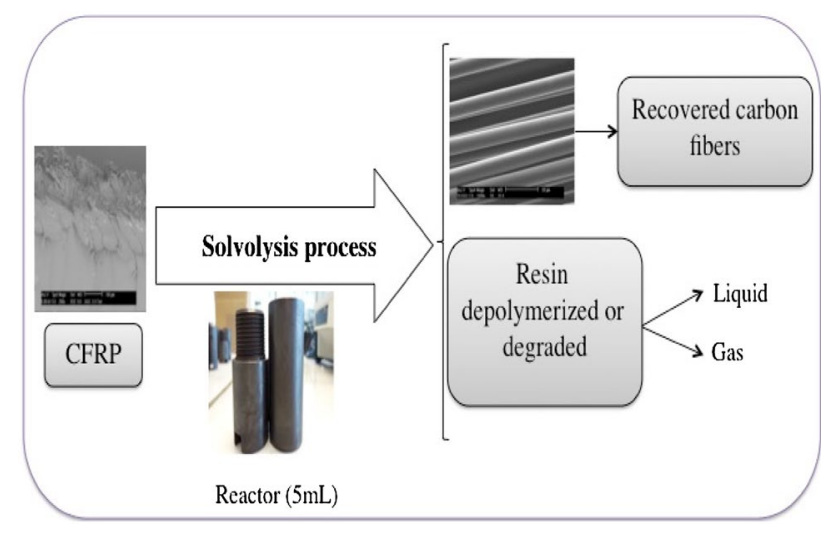

Fig. 1 Principle of the experimental setup

$\left(400-600{ }^{\circ} \mathrm{C}\right)$. Then, the reactors were introduced in the oven. The reaction time started as the reactor reached the desired temperature. At the end of the experiments, the reactor was cooled down to room temperature and the three phases (solid, liquid, and gas) were separated. The volume of gas and the mass of the solid were measured. The results are provided in terms of resin removal rather than total mass loss calculated as follows:

\section{Solid Phase Analysis}

The fibers recovered were analyzed by environmental scanning electron microscopy (ESEM Philips XL30 FEG) with a Back-scattering electron detector in order to observe their physical appearance.

The microstructure parameters of the virgin carbon fibers was analysed by Confocal Raman WITEC Alpha 300AR microscope. A CCD (charge-coupled device) camera detector $\left(175-4000 \mathrm{~cm}^{-1}\right)$ was used to collect the Raman spectra. The analysis was performed at room temperature. Laser with $532 \mathrm{~nm}$ wavelength was used as an illumination source. For each spectrum, five scans were collected and co-added in the instrument control computer. Spectra were compared and an average spectrum was used to represent each sample.

The tensile strengths (INSTRON 5942) of the virgin and recovered fibers were measured. The fibers length used was $35 \mathrm{~mm}$. The tensile testing was performed on a testing frame with $5 \mathrm{~N}$ load cell and a crosshead speed of $1 \mathrm{~mm} /$ min. The obtained values were processed on the one hand by an analysis based on normal distribution (mean value, standard deviation) conform to the standard norm ISO 11566. The reported tensile strengths were the mean value

Resin removal $(\%)=\frac{\text { weight of composite }- \text { weight of solid residue }}{\text { Weight of resin in composite }} \times 100$

\section{Liquid Phase Analysis}

The Total organic carbon in the aqueous phase was measured using a TOC analyzer (Shimadzu TOC$\mathrm{VCSH})$. The amount of carbon in the liquid phase was then calculated assuming a constant volume of water after reaction. Then the percentage of carbon from the resin and recovered in the liquid phase is calculated following Eq. 2.

Carbon amount $(\%)=\frac{\text { weight of carbon in the liquid phase }}{\text { weight of carbon in the resin }} \times 100$

The molecules present in the liquid phase were analyzed by GC-MS (GC-MS-TQ8030, Shimadzu). The capillary column (ZB-5MS) used was $95 \%$ nonpolar and $5 \%$ polar, $30 \mathrm{~m}$ of length and $0.025 \mathrm{~mm}$ of inner diameter. The carrier gas was helium at a constant flow rate $1.56 \mathrm{~mL} / \mathrm{min}$. The $\mathrm{GC}$-injector was at $250^{\circ} \mathrm{C}$. The furnace temperature was at $40^{\circ} \mathrm{C}$ held for $2 \mathrm{~min}$ and ramped to $280^{\circ} \mathrm{C}$ at a rate of $10^{\circ} / \mathrm{min}$ and then held at $280^{\circ} \mathrm{C}$ for $4 \mathrm{~min}$. The interface temperature was $280^{\circ} \mathrm{C}$. Spectral searches on the installed NIST11 and NIST11s Libraries were used to qualitatively identify the major unknown compounds in the liquid phase. of 40 measurements. On the other hand, Weibull analysis [33], a widely used method for the analysis of fragile materials as carbon fibers $[15,34]$ was also utilized to evaluate the results. 40 specimens in each condition were tested. In Weibull-weakest link model, the fiber is supposed to be constituted of different links having each one its tear resistance. The break occurs when the weakest link is broken. For each link, it is attributed a failure probability. The distribution function of the two-parameter Weibull used to describe the fiber strength parameters is in the equation below [34]:

$P=1-\exp \left[-\left(\frac{\sigma}{\sigma_{0}}\right)^{m}\right]$

where $\mathrm{P}$ is the cumulative failure probability, $\sigma$ the applied stress, $\mathrm{m}$ is the Weibull shape parameter and $\sigma_{0}$ is the Weibull scale parameter.

This cumulative failure probability, under a particular stress is approximated by:

$P=\frac{(i-0.5)}{N}$

where $\mathrm{i}$ is the number of fiber that have broken at a stress level and $\mathrm{N}$ is the total number of fibers tested. After 
simplification and linearization, the plot of $\ln [-\ln (1-\mathrm{P})]$ versus $\ln (\sigma)$ is commonly used for a given sample length to derive the Weibull shape parameter, $\mathrm{m}$, and the scale parameter, $\sigma_{0}$. It results to a linear relationship with a slope, m.

$\ln (-\ln (1-P))=m \ln (\sigma)-m \ln \left(\sigma_{0}\right)$

\section{Kinetics Parameters}

Kinetics of PA6 can be treated as a pseudo-first-order reaction since water concentration is expected to be constant. Decomposition kinetics of resin is described using the following equations:

$$
\begin{aligned}
& \frac{-d[P A 6]}{d t}=k[P A 6]^{\propto} H_{2} O^{\beta} \\
& \frac{-d[P A 6]}{d t}=k_{\text {app }}[P A 6]^{\propto} \text { avec }_{\mathrm{app}}=k H_{2} O^{\beta} \\
& \frac{-d m_{P A 6}}{d t}=k_{\text {app }} m_{P A 6} \quad \text { avec } \propto=1 \\
& \operatorname{Ln}\left(\frac{m_{0}}{m_{P A 6}}\right)=k_{\text {app }} t
\end{aligned}
$$

where (PA6) is the concentration of PA6, $\propto$ is thepartial order of PA6, $\beta$ is the partial order of $\mathrm{H}_{2} \mathrm{O}, \mathrm{m}_{0}$ is the initial mass of PA6 and $m_{P A 6}$ is the residual mass of PA6 at $\mathrm{t}, \mathrm{k}$ is the rate constant and $t$ is the reaction time.

The activation energy is calculated by the Arrhenius equation

$k=A e^{\frac{-E_{\mathrm{a}}}{\mathrm{RT}}}$

where $\mathrm{K}$ is the rate constant, $\mathrm{A}$ is the pre-exponential factor, $\mathrm{E}_{\mathrm{a}}$ is the activation energy, $\mathrm{R}$ is the gas constant and $\mathrm{T}$ is the temperature.

\section{Results and Discussion}

Solvolysis was performed to remove the PA6 resin from the composite and to recover carbon fibers. Using this process, resin could be dissolved in the liquid phase (depolymerization), remained in the solid phase (not efficient or charring issues) or converted in volatile molecules in gaseous phase (degradation). Several experiments in subcritical $\left(280-350^{\circ} \mathrm{C}\right)$ and supercritical water $\left(400-600^{\circ} \mathrm{C}\right)$ were carried out in order to evaluate the resin decomposition as well as the properties of recovered carbon fibers over reaction time (1-120 min).

As mentioned previously, this study is focused on two key points. On the one hand, a preliminary study is made in subcritical and supercritical water in order to understand the conversion of the reaction of resin decomposition. Then, a kinetic study was realized in order to compare the kinetic parameters in sub and supercritical regions. On the other hand, the properties of recovered carbon fibers are measured and compared to the virgin ones since the main issue regarding the reuse of recovered carbon fibers is their mechanical properties.

\section{Efficiency of Solvolysis Treatment}

This section is dedicated to the evaluation of solvolysis efficiency. Efficiency is first evaluated using the resin removal (Eq. 1) over the solvolysis treatment.

\section{Conversion using subcritical water}

Figure 2 shows the results of the decomposition efficiency (resin removal) as a function of reaction time at each reaction temperature: 280,310 and $350{ }^{\circ} \mathrm{C}$. The amount of resin eliminated from the solid residue increased rapidly with reaction time using the three reaction temperatures considered. The maximal rate reached almost $100 \%$ after 15 to 30 min of reaction time, and then is quite stabilized to the maximal value. This observation is confirmed by ESEM pictures, in the Fig. 3, in which the fibers are well-separated from balls of resin deposited, even if some resin deposits are locally still observed. We also noted that there are no visible damages on carbon fibers surface using ESEM resolution. Figure 2 shows that the process efficiency (resin removal) increased linearly during the first moments of reaction. This linear domain was (5-30min) at 280 and $310^{\circ} \mathrm{C}$, and decreased to (5-15min) at $350{ }^{\circ} \mathrm{C}$. Thus, the kinetics of the reaction is faster as the temperature increased.

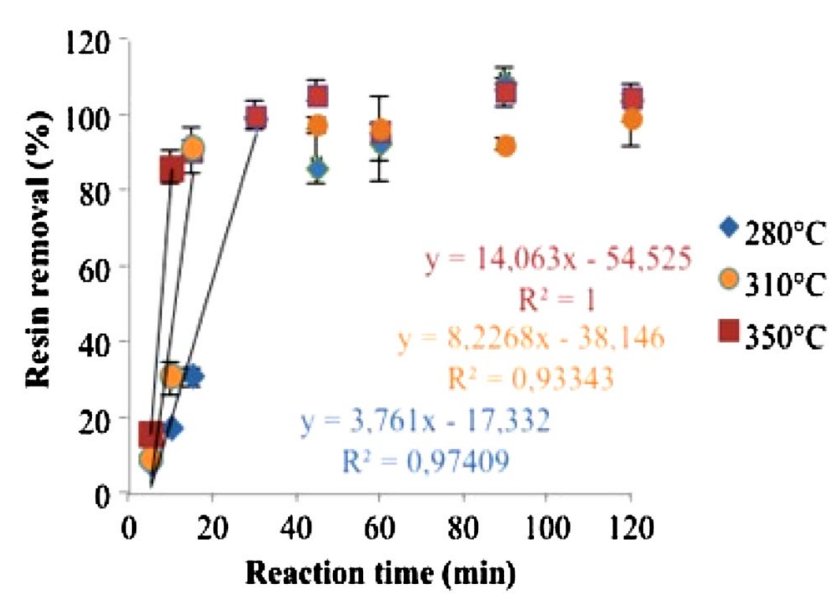

Fig. 2 Resin removal versus reaction time at 280,310 , and $350^{\circ} \mathrm{C}$ 

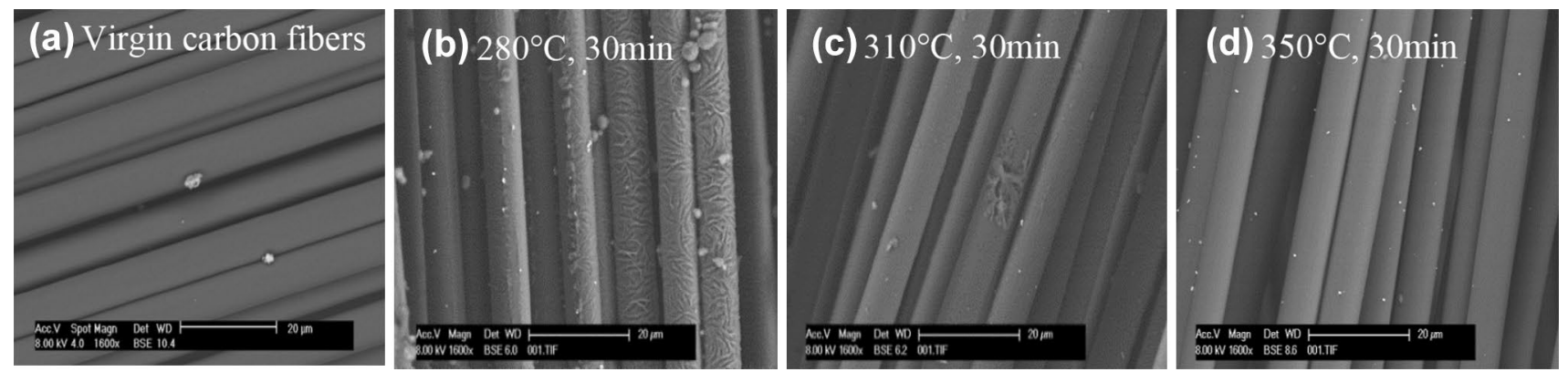

Fig. 3 ESEM micrographs of virgin carbon fibers and remaining composite after solvolysis using ultrapure water at $30 \mathrm{~min}$

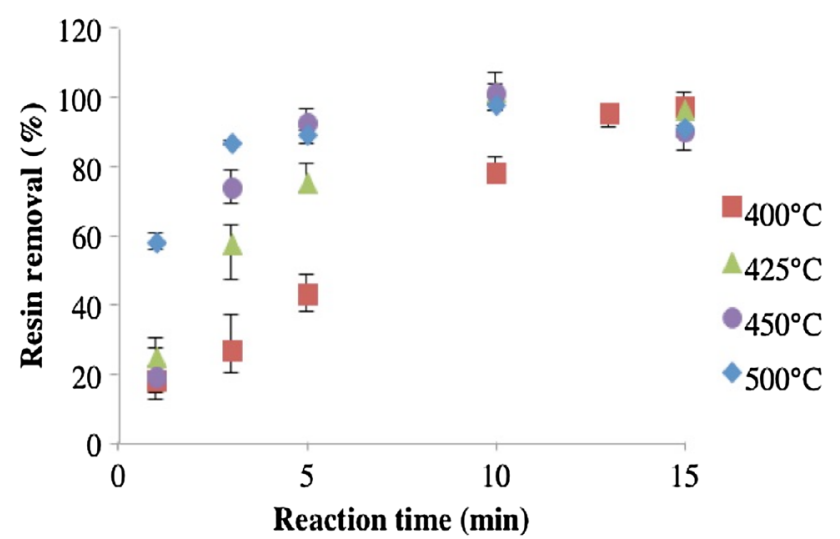

Fig. 4 Resin removal versus reaction time at 400, 425, 450 and $500^{\circ} \mathrm{C}$

\section{Conversion Using Supercritical Water}

Figure 4 presents the resin removal using supercritical conditions. Reaction temperature was set at 400, 425, 450 and $500^{\circ} \mathrm{C}$. The resin removal increased rapidly at short reaction time, for the different temperatures used. The maximal value close to $100 \%$ was reached for less than 15 min of reaction time. Figure 5 presents ESEM pictures of some remaining solids and shows that the surface of fibers recovered are quite close to that of the virgin carbon fibers. No particular damages were highlighted. Otherwise, small white particles are observed on the fibers surface. EDS micro-analysis confirmed that these particles are attributed to titanium. These particles may be due to the impurities present on the precursor of PAN [35] and/or from the surface treatment of carbon fibers surface in order to improve the chemical compatibility of fibers and resin [36].

We noted that at $500^{\circ} \mathrm{C}$, gaseous phase was generated. It was reported that high temperatures $\left(\geq 500^{\circ} \mathrm{C}\right)$ promote gasification, while low temperatures favor liquefaction [37, 38]. Regarding literature, the reactions involved at sub and supercritical conditions should be different [37]. Ionic reactions are expected to be improved at subcritical conditions while radical reactions are enhanced in supercritical water. As for the reaction in subcritical conditions, the evolving is quite linear during the first reaction times and then reached a plateau. The time required to achieve the resin elimination is lower than using subcritical conditions meaning that the kinetics has been improved with the temperature and the state of water. Therefore, kinetics in sub and supercritical conditions are studied in the next section.

\section{Kinetics Study in Sub and Supercritical Water}

In this section, kinetics in sub and supercritical regions is discussed. Figure 6 shows $\ln \left(\mathrm{m}_{0} / \mathrm{m}\right)$ versus reaction time at 280,310 and $350{ }^{\circ} \mathrm{C}$, and at $400,425,450$ and $500^{\circ} \mathrm{C}$. In
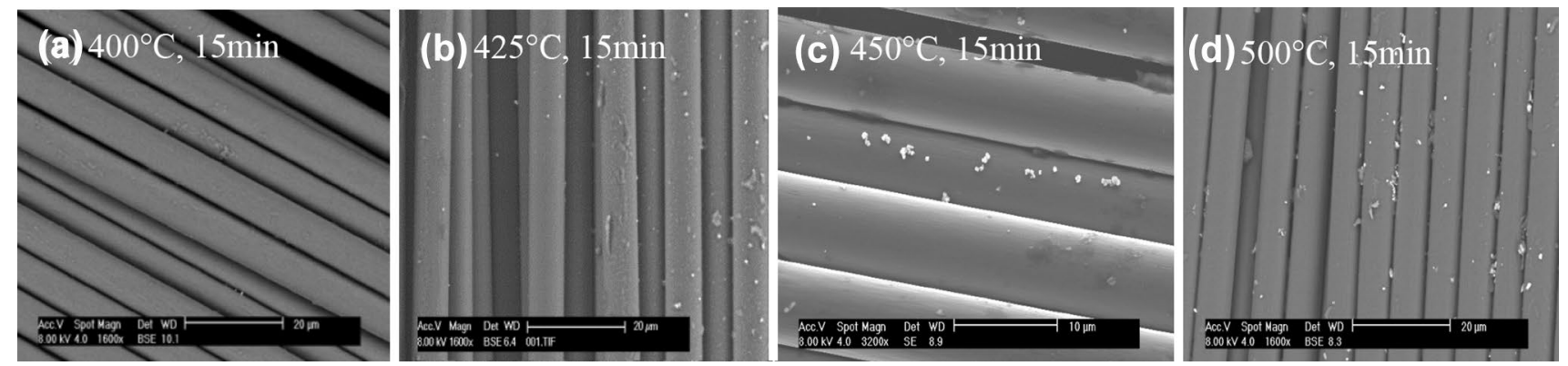

Fig. 5 ESEM micrographs of remaining composite after solvolysis using ultrapure water at 15 min 

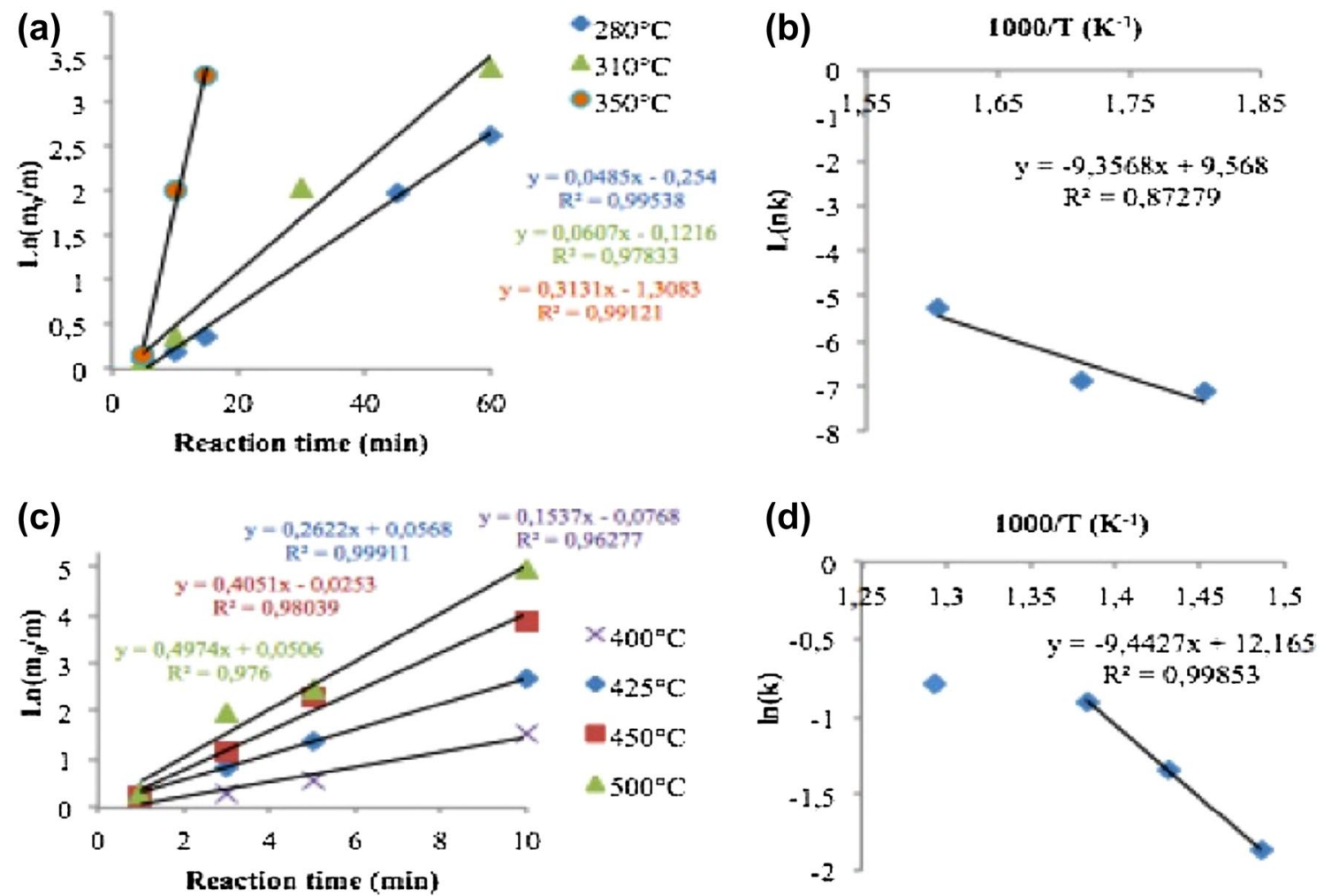

Fig. $6 \ln \left(\frac{m_{0}}{m}\right)$ versus reaction time and $\ln (\mathrm{k})$ versus $(1 / T)$ in subcritical water $(\mathbf{a}, \mathbf{b})$ and supercritical water $(\mathbf{c}, \mathbf{d})$

addition $\ln (\mathrm{k})$ versus $(1 / \mathrm{T})$ is also plotted in order to determine the activation energies.

Figure 6a, c show that the pseudo-first order describes properly the experimental results both in subcritical conditions $\left(350,310\right.$ and $\left.280^{\circ} \mathrm{C}\right)$ and in supercritical conditions $\left(400-500^{\circ} \mathrm{C}\right)$. Using these data, the objective is to determine the activation energy (Fig. 6b, d). At subcritical condition, the three points are clearly giving a straight line, thus activation energy was equal to $77.79 \mathrm{~kJ} / \mathrm{mol}$. In the supercritical domain, the four points are not aligned in a straight line. However, using data from 400 to $450{ }^{\circ} \mathrm{C}$ a straight line is drawn giving activation energy of $78.51 \mathrm{~kJ} /$ mol. As mentioned previously, the experiments carried out at $500{ }^{\circ} \mathrm{C}$ showed quantitative gas production. In this context, the mechanism pathway should be different and could explain the non-linearity of the Arrhenius plot in Fig. 6 . Both values are similar meaning that the global reactions involved should be the same in both regions. This activation energy corresponds to the depolymerization of the resin into different lighter molecules (oligomers and monomers). Iwaya et al. [39] experimentally determined activation energy of $97.1 \mathrm{~kJ} / \mathrm{mol}$ in the range of temperature $300-360^{\circ} \mathrm{C}$. However, the authors studied precisely the reaction from pure PA6 sheet to 6-aminocaproic acid, while the present study only follows the disappearance of PA6 mass. Therefore the experimental value should mean that the global reaction is not so far from a depolymerization.

\section{Suggested Reaction Schemes}

In order to provide a reaction scheme, the first question is to determine whether the resin removal is a depolymerization or degradation pathway. As seen in the previous section, the activation energy value would direct to a depolymerization phenomenon.

Figure 7 shows the resin removal versus the carbon amount recovered in the liquid phase. At the beginning (less than $30 \mathrm{~min}$ at subcritical conditions) the curves follow a linear trend. In addition, the slope is very close to 1 . This informs that the resin is totally decomposed in lighter molecules dissolved in the liquid phase and means that the polyamide 6 is depolymerized. At supercritical conditions, a linear trend is obtained up to $450{ }^{\circ} \mathrm{C}$ but the carbon amount should be underestimated compared to the rate of resin eliminated since the slope is not equal to 1 . This gap between carbon amount and the resin removal could be due to the suspension materials remained in liquid phase. From $500^{\circ} \mathrm{C}$, the trend of curves changes and follows a polynomial trend which suggests a different mechanism of decomposition of the resin. Thus, the reaction involved in both 



Fig. 7 Resin removal versus amount of carbon present in liquid phase in sub (a) and supercritical conditions (b)

subcritical and supercritical water near to critical region is a depolymerization rather than a degradation since no gaseous phase was recovered in these conditions. In supercritical conditions above $500^{\circ} \mathrm{C}$, the two reactions types are supposed to occur due to gas production.

At the atomic scale in the domain of linearity, the reaction of decomposition should begin with the shrinking of oligomers and monomers from the resin. GC-MS analysis revealed the presence of $\varepsilon$-caprolactam (monomer of PA6) and other molecules in sub and supercritical conditions. At short reaction times (5 and $10 \mathrm{~min}$ depending on temperature), only the molecules of $\varepsilon$-caprolactam were identified. Heavier and lower molecules than $\varepsilon$-caprolactam were also identified at longer reaction times: 1-8-Diazacyclotetradecane-2,9,-dione, 1-Methylcaprolactam, 2-oxepanone, 7-hexyl, trans-2-hexene, 6-Hydroxyhexanoic acid, 1-cyclopentene-1-carboxylic acid and cyclopentanone. In the presence of nucleophile, the weakness is situated on the peptide bond which is hydrolyzed from $280^{\circ} \mathrm{C}$ and also on the alkyl-amid bonds which undergo homolytic scission at temperature greater than $500^{\circ} \mathrm{C}$ [40]. As reported in the literature [11] the depolymerization of PA6 into $\varepsilon$-caprolactam could produce an intermediate which is the 6-aminocaproic acid as presented in the Fig. 8. In the range of temperature $200-300^{\circ} \mathrm{C}$, ionic product of water increases up to around $10^{-11}$ [37]. To form 6-aminocaproïc acid, the decomposition reaction should be initiated on the carbon nitrogen bond $(\mathrm{C}-\mathrm{N})$. In the subcritical water medium, $\mathrm{H}^{+}$ions could react with the amide functional group to form ammonium functional group. This center of positive charges induces the hydroxylation of the carbon in the amide functional group. The carbonyl group is thus transformed into a carboxylic acid group. The amine and the carboxylic acid are functional groups existing in both sides of the molecule. The resulting molecule is 6-aminocaproic acid. However, this intermediate was not detected by GC-MS. The reaction is likely very fast and does not let us identify it. Finally, 6-aminocaproic acid quickly dehydrates and cyclizes to produce $\varepsilon$-caprolactam.

To summarize, the reaction scheme of PA6 depolymerization would be the hydrolysis of amides to form 6-aminocaproic acid followed by the cyclodehydration of 6-aminocaproic acid to $\varepsilon$-caprolactam [41, 42]. This type of chemical scission is supported by Chen et al. [42] and Iwaya et al. [39].

A scheme reaction is proposed in Fig. 9: $\varepsilon$-caprolactam could be transformed into 1-Methylcaprolactam or could react with another identical molecule to produce 1-8-Diazacyclotetradecane-2,9,-dione. This latter could be transformed into 2-oxepanone, 7-hexyl. The trans-2-hexene should come from the degradation of 2-oxepanone, 7-hexyl. However, 6-hydroxyhexanoic acid could come either from the degradation of 2-oxepanone, 7-hexyl or from the ring cleavage of caprolactone [41]. 6-hydroxyhexanoic acid could react with ammonia in order to form 6-hydroxyhexanamide which could undergo an intramolecular dehydration to form $\varepsilon$-caprolactam.

The detection of heavier molecules than caprolactam suggests a repolymerization phenomenon which could occur as reported in literature [37]. In fact, the decomposition of phenols due to poly-condensation reactions leads to the formation of different short chain polymers. From these
Fig. 8 Depolymerization of PA6 to $\varepsilon$-caprolactam [41]

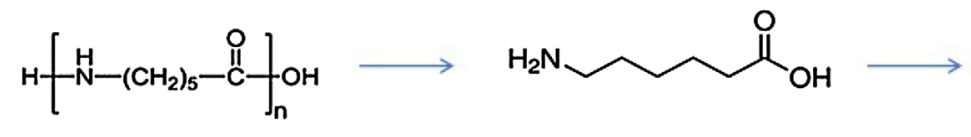

PA6

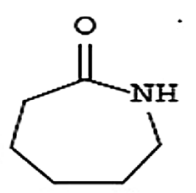

$\varepsilon$-caprolactam 


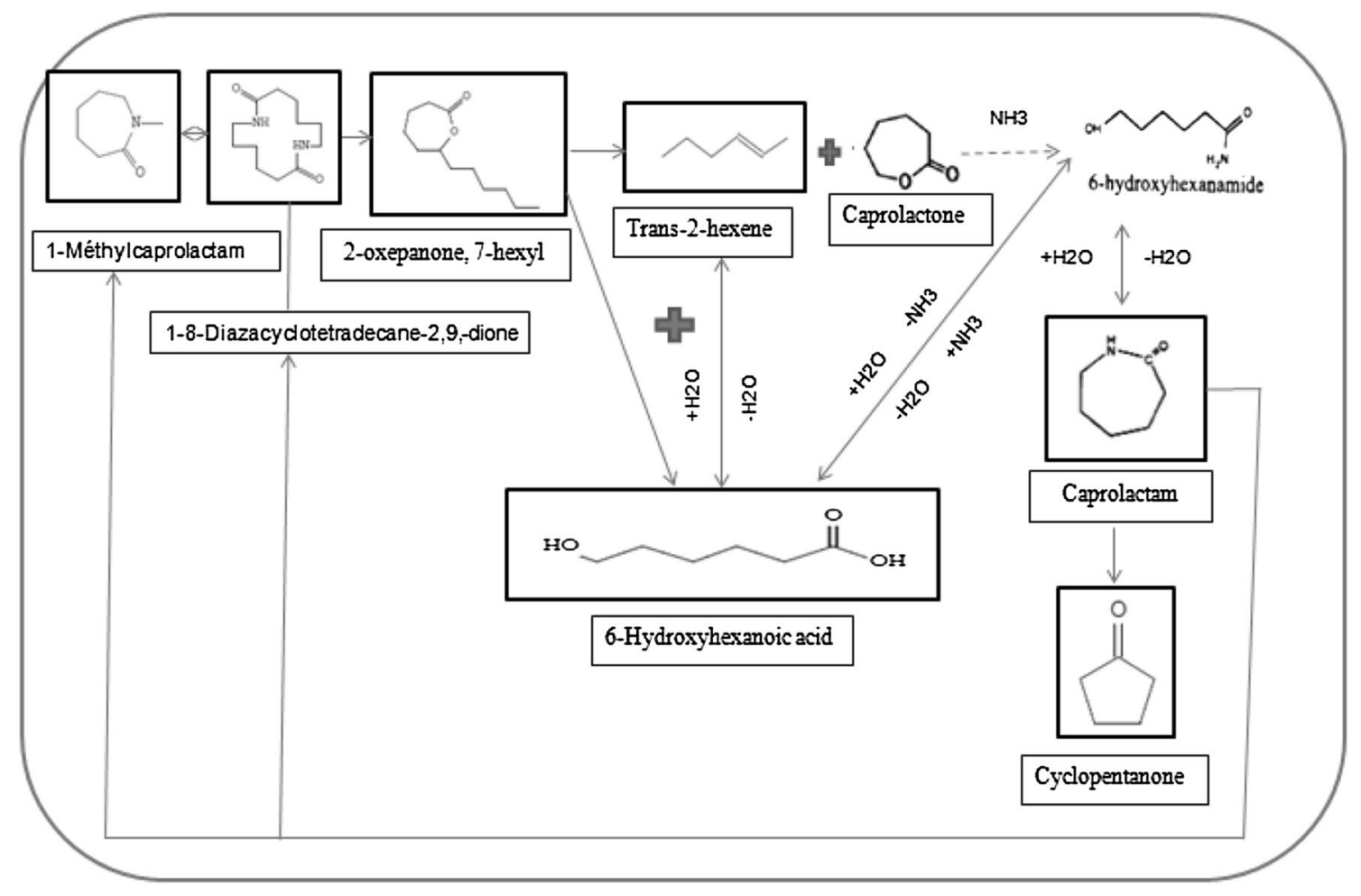

Fig. 9 Reaction scheme (framed molecules are detected by GC-MS)

intermediates, gases and coke formation occurs. In addition, Yong and Matsumura [43] stated that the decomposition of phenol in water at near-critical conditions leads to a competition between gas and char formation. Repolymerization of degradation products could produce a layer that remained on the recovered carbon fibers surface after cooling. In order to confirm or deny this hypothesis, molecules contained in liquid phase should be analyzed and quantified at longer reaction time.

The efficiency of the process was validated. It remains to complete the characterization of recovered carbon fibers and especially to determine their mechanical properties as it is the most important data for recycling in order to select the best conditions able to provide good quality carbon fibers.

\section{Properties of Recovered Carbon Fibers}

Recovered carbon fibers are especially characterized regarding their mechanical properties for further use.

\section{Mechanical Properties}

The fibers obtained in sub- and supercritical conditions were subjected to tensile strength tests. All the recovered fibers were analyzed. As mentioned in Figs. 2 and 4, reaction times of 15 and $30 \mathrm{~min}$ are sufficient to provide maximal resin elimination. Therefore, Table 1 only lists the mechanical properties measured for the "optimal" reaction time at each temperature. Tensile properties should be compared to that of the virgin carbon fibers $(4931.29 \pm 530 \mathrm{MPa})$. Results were studied by normal distribution based on the mean value and standard deviation, the method commonly used in order to determine the tensile strength of carbon fibers and by Weibull distribution which evaluate distribution of the default size in carbon fibers.

As shown in Table 1, the tensile strength of recovered carbon fibers is not affected by solvolysis treatment in both regions. The values of tensile strength of recovered carbon

Table 1 Mechanical properties of recovered carbon fibers in subcritical and supercritical water

\begin{tabular}{lllll}
\hline Water state & $\begin{array}{l}\text { Reaction } \\
\text { time }(\min )\end{array}$ & $\begin{array}{l}\text { Tempera- } \\
\text { ture }\left({ }^{\circ} \mathrm{C}\right)\end{array}$ & $\begin{array}{l}\text { Tensile strength } \\
(\mathrm{MPa})\end{array}$ & $\begin{array}{l}\text { Standard } \\
\text { deviation }\end{array}$ \\
\hline Subcritical & 30 & 280 & 4240.93 & 906 \\
& 30 & 310 & 4233.56 & 635 \\
& 30 & 350 & 4128.58 & 572 \\
Supercritical & 15 & 400 & 4575.03 & 940 \\
& 15 & 425 & 4061.97 & 788 \\
& 15 & 450 & 4161.87 & 449 \\
& 15 & 500 & 4239.45 & 690 \\
\hline
\end{tabular}


fibers are situated in the $10 \%$ of the margin of error of the tensile strength of virgin carbon fibers. It means that the process is suitable for obtaining fibers with good mechanical properties. Besides, the values of standard deviation of recovered carbon fibers are higher than that of virgin carbon fibers, meaning that the tensile strength values are more dispersed over the selected fibers. This observation would be a key item since this deviation indicates that the sizes of defaults originating the rupture are more heterogeneous. These defaults could be due to physical or chemical treatment. The physical treatment improves surface roughness which could serve as mechanical anchorings [44, 45]. The chemical treatment adds some oxygenated functions at the surface. Bai et al. [12] studied the chemical recycling of carbon fibers reinforced epoxy resin using supercritical water oxidation. They concluded that oxygenated groups on carbon fibers microstructure impacted their mechanical properties, since they observed a loss of $38 \%$ in tensile strength for a decomposition efficiency of $100.2 \mathrm{wt} \%$. However, in our case, the impact of chemical treatment is not as strong as in the last cited study since tensile strength values of treated fibers are closed to virgin fibers values.

In order to evaluate the distribution of defaults, Weibull parameters were also studied.

Table 2 shows the Weibull parameters obtained on the fibers treated at sub and supercritical conditions. These parameters are Weibull shape parameter, $\mathrm{m}$, and the scale parameter, $\sigma_{0}$. The latter reflects the average stress cracks activation causing the fiber break. The Weibull parameter $m$ translated meanwhile, the dispersion of defects in the fiber. As $\mathrm{m}$ is big, the greater the defect distribution is fine. Weibull parameters seem to be coherent with the analysis based on normal distribution. In fact, the same observations are faithfully transcript compared to normal distribution considering the scale parameter $\sigma_{0}$. Otherwise, the Weibull shape parameters are coherent with the standard deviations. As the standard deviation increases, the heterogeneous

Table 2 Weibull mechanical properties of virgin carbon fibers (VCF) and recovered carbon fibers (RCF) in subcritical and supercritical water

\begin{tabular}{llll}
\hline Water state & Samples & $\begin{array}{l}\text { Weibull } \\
\text { parameter } \\
\mathrm{m}\end{array}$ & $\begin{array}{l}\text { Scaling } \\
\text { factor } \sigma_{0} \\
(\mathrm{MPa})\end{array}$ \\
\hline- & $\mathrm{VCF}$ & 7.90 & 5126.36 \\
Subcritical water & $\mathrm{RCF}\left(280^{\circ} \mathrm{C}, 30 \mathrm{~min}\right)$ & 5.60 & 4596.50 \\
& $\mathrm{RCF}\left(310^{\circ} \mathrm{C}, 30 \mathrm{~min}\right)$ & 8.08 & 4493.52 \\
& $\mathrm{RCF}\left(350^{\circ} \mathrm{C}, 30 \mathrm{~min}\right)$ & 8.71 & 4367.81 \\
Supercritical water & $\mathrm{RCF}\left(400^{\circ} \mathrm{C}, 15 \mathrm{~min}\right)$ & 5.65 & 4953.52 \\
& $\mathrm{RCF}\left(425^{\circ} \mathrm{C}, 15 \mathrm{~min}\right)$ & 6.03 & 4382.34 \\
& $\mathrm{RCF}\left(450^{\circ} \mathrm{C}, 15 \mathrm{~min}\right)$ & 9.37 & 4387.29 \\
& $\mathrm{RCF}\left(500^{\circ} \mathrm{C}, 15 \mathrm{~min}\right)$ & 7.45 & 4519.75 \\
\hline
\end{tabular}

is the breakage and the lower is the Weibull parameter. Table 2 shows that treated fibers in subcritical water present Weibull parameter lower than the one of virgin carbon fibers at $280^{\circ} \mathrm{C}$. This is probably due to resin impurities still deposited on carbon surface (seen on ESEM picture Fig. 3b). However, at 310 and $350^{\circ} \mathrm{C}$, the Weibull parameters of treated fibers are higher than that of the virgin fibers. This could be due probably to an artefact in measurements. In supercritical water, Weibull parameters values are lower than that of virgin carbon fibers except at $450^{\circ} \mathrm{C}$. Thus, the distribution of defect seems to be larger in supercritical region than in subcritical region. These defects could be structural defects in the graphitic structure. In order to understand these eventual changes in carbon structure, structural properties are studied in the next section.

\section{Structural Properties}

Mechanical properties and ESEM observations informed that the treatment applied is not so severe to oxidize or to create visible cracks on the recovered carbon fibers. However the results from the previous section highlight that the carbon fibers are modified in their micro or nanostructure. For this purpose, Raman spectroscopy has been used since it informs on bond vibration mode in a molecule, and therefore gives information on carbon hybridization. Basically, the $G$ and $D$ bands are the broad bands related to the "pure" graphitic structures and to the defects in the graphene sheets respectively. In addition, the height of the valley (D and $G$ bands overlapping) corresponds to the amorphous content. Fig. 10 presents some Raman spectra, namely that obtained for virgin carbon fibers and for the recovered carbon fibers in "optimal conditions" $350{ }^{\circ} \mathrm{C}$, $30 \mathrm{~min}$ and $400^{\circ} \mathrm{C}, 15 \mathrm{~min}$. The Raman spectrum shows in the first order region (800-2000 $\mathrm{cm}^{-1}$ ) two main broad and overlapping peaks with maximum intensities at 1350 and $1590 \mathrm{~cm}^{-1}$. These two peaks are attributed to the $\mathrm{D}$ and $\mathrm{G}$ bands respectively. The $\mathrm{G}$ band corresponds to the $\mathrm{sp}^{2}$ carbon atoms in the graphitic structure (aromatic rings) [46]. The D band, whose origin had long been debated by Tunistra and Koenig [47] and Ferrari et al. [48] corresponds to the defects in the graphitic structure [46]. It can be seen that the $\mathrm{G}$ band intensity is higher than that of $\mathrm{D}$ band for the virgin carbon fiber. On the contrary, the intensity of the $\mathrm{D}$ band becomes higher for recovered carbon fibers. This first observation indicates that the "pure graphitic" structures are consumed in favor to disordered graphitic structures since the height of the valley is kept constant. Overall, it could be deduce that defects induced in the graphitic nanostructures could come from "fullerene-like" structures, carbon nanotubes arranged in onion-like structures, pointdefects (edges), nanocrystallites reorganization and so on [49-52]. In addition, Fig. 10 shows that $\mathrm{G}$ and $\mathrm{D}$ bands are 


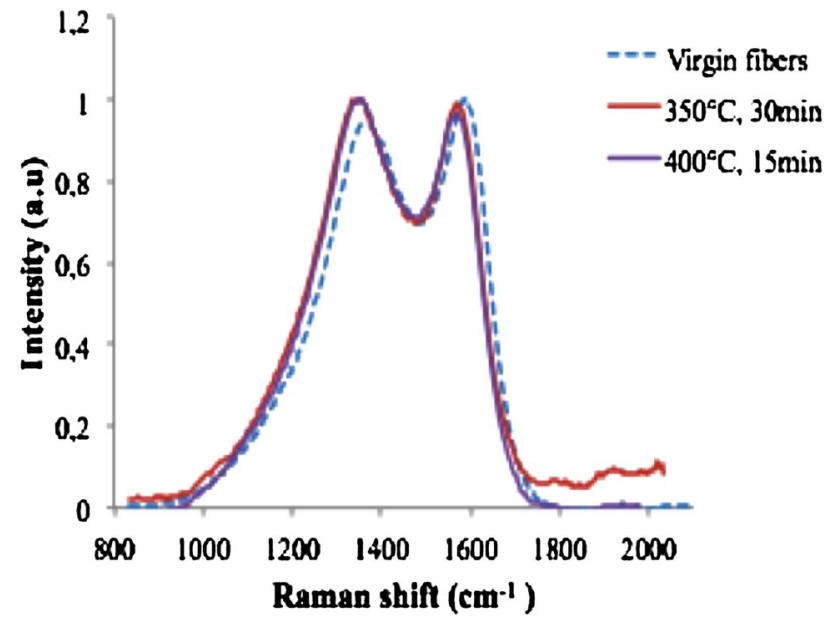

Fig. 10 Raman spectra of the virgin and recovered carbon fibers

slightly red-shifted from virgin carbon fibers to recovered fibers. D band maximum is shifted from 1370 to 1340 and $1350 \mathrm{~cm}^{-1}$ for experiments carried out at 350 and $400^{\circ} \mathrm{C}$ respectively. The $\mathrm{G}$ band maximum is shifted from 1590 to $1580 \mathrm{~cm}^{-1}$. McDonald-Warry et al. concluded that a red shift in the $\mathrm{D}$ and $\mathrm{G}$ bands position would mean that the graphitic structure is reorganized and would contain a large part of defects, and curved graphene fringes which are greatly organized (or distributed). Although the D band intensity could be related to the size of nanocrystallites (meaning size of defects), the current results are not precise enough to led to this conclusion. However it can be concluded that nanostructural changes occurred during the solvolysis. These changes seem to slightly modify the mechanical properties. Deepest investigations should be developed to better understand the relation between mechanical properties and nanostructure.

\section{Conclusions}

The aim of this work is to study the solvolysis of PA6 based composite in order to recover simultaneously carbon fibers and to valorize resin. The ability of water as solvent-reagent for chemical recycling of carbon fibers reinforced PA6 has been investigated in sub and supercritical conditions. On the one hand, experiments were performed at 280,310, and $350^{\circ} \mathrm{C}$ and $25 \mathrm{MPa}$ for reaction times ranging from 5 to $120 \mathrm{~min}$. On the other hand, experiments were performed at $400,425,450$, and $500^{\circ} \mathrm{C}$ and $25 \mathrm{MPa}$ for reaction times ranging from 1 to $15 \mathrm{~min}$. The resin decomposition was accelerated in supercritical water than in subcritical water. The resin removal reached $98.95 \mathrm{wt} \%$ at $280^{\circ} \mathrm{C}$ in $30 \mathrm{~min}$ while, It has already reached $97.18 \mathrm{wt} \%$ at $400^{\circ} \mathrm{C}$ in only $15 \mathrm{~min}$. Kinetics was studied as a pseudo-first-order reaction. The activation energy was 77.99 and $78.51 \mathrm{~kJ} /$ mol in sub and supercritical water respectively. Thus, the reaction mechanism of the decomposition of the resin is the same in both regions. In addition, the same molecules were identified in liquid phases recovered from both conditions. In fact, resin was completely decomposed into $\varepsilon$-caprolactam and other molecules. Only $\varepsilon$-caprolactam was detected in liquid phase recovered in short reaction times (10-30min). Above 15-30min (depending on the temperature), heavier molecules were detected. Thus, a repolymerization phenomenon was supposed to occur. Tensile strength of recovered fibers was very close to that of virgin fibers. Weibull parameters show that the distribution of defects seems to be lager in subcritical water than in supercritical water. In microscopic view, Raman analysis show slight modifications at carbon structure on fibers surface. These microstructural changes could be due to repolymerization phenomenon and may be correlated with the large distribution of defects. Further studies are in progress to investigate the repolymerization phenomenon and its impact on mechanical and structural properties of carbon fibers.

Acknowledgements The authors acklowledge Christine Rolland, Laurène Haurie and Jean-Marie Sabathier for their assistance with analysis.

\section{References}

1. Bernhard, J.: The global CRP market: carbon composites (2013)

2. Pickering, S.J.: Recycling technologies for thermoset composite materials-current status. Compos. Part A. 37, 1206-1215 (2006)

3. Oliveux, G., Bailleul, J.L., La Salle, E.L.G.: Chemical recycling of glass fibre reinforced composites using subcritical water. Compos. Part A. 43, 1809-1818 (2012)

4. Garcia, D., Vegas, I., Cacho, I. Mechanical recycling of GFRP waste as short-fiber reinforcements in microconcrete. Constr. Build. Mater. 64, 293-300 (2014)

5. Ana, C., Castro, M., Carvalho, J.P., Ribeiro M.C.S., Meixedo, J.P., Silva, F.G.J., Fiúza, A., Dinis, M.L.D.: An integrated recycling approach for GFRP pultrusion wastes: recycling and reuse assessment into new composite materials using Fuzzy Boolean Nets. J. Clean. Prod. 66, 420-430 (2014)

6. Kouparitsas, C.E., Kartalis, C.N., Varelidis, P.C., Tsenoglou, C.J, Papaspyrides, C.D.: Recycling of the fibrous fraction of reinforced thermoset composites. Polym. Compos. 23, 682-689 (2002)

7. Ogi, K., Nishikawa, T., Okano, Y., Taketa, I.: Mechanical properties of ABS resin reinforced with recycled CFRP. Adv. Compos. Mater. 16, 181-194 (2007)

8. Ushikosha, K., Komatsu, N., Sugino, M.: Recycling of CFRP by pyrolysis method. J. Soc. Mater. Sci. Jpn. 44(499), 428-431 (1995)

9. Ye, S.Y., Bounaceur, A., Soudais, Y., Barna, R.: Parameter optimization of the steam thermolysis: a process to recover carbon fibers from polymer-matrix composites. Waste Biomass Valoriz. 4, 73-86 (2013) 
10. Morin, C., Loppinet-Serrani, A., Cansell, F., Aymonier, C.: Near- and supercritical solvolysis of carbon fibre reinforced polymers (CFRPs) for recycling carbon fibers as a valuable resource: state of the art. J. Supercrit. Fluid. 66, 232-240 (2012)

11. Pinero-Hernanz, R., Dodds, C., Hyde, J., Garcia-Serna, J., Poliakoff, M., Lester, E., Cocero, M.J., Kingman, S, Pickering, S., Wong, H.K.: Chemical recycling of carbon fibre reinforced composites in nearcritical and supercritical water. Compos. Part A. 39, 454-461 (2008)

12. Bai, Y., Wang, Z., Feng, L.: Chemical recycling of carbon fibers reinforced epoxy resin composites in oxygen in supercritical water. Mater. Des. 31, 999-1002 (2010)

13. Onwudili Jude, A., Yildirir E., Williams Paul T.: Catalytic hydrothermal degradation of carbon reinforced plastic wastes for carbon fibre and chemical feedstock recovery. Waste Biomass Valoriz. 4, 87-93 (2013)

14. Pinero-Hernanz, R., Garcia-Serna, J., Dodds, C., Hyde, J., Poliakoff, M., Cocero, M.J., Kingman, S., Pickering, S., Lester, E.: Chemical recycling of carbon fibre composites using alcohols under subcritical and supercritical conditions. J. Supercrit. Fluids 46, 83-92 (2008)

15. Jiang, G., Pickering, S.J., Lester, E.H., Turner, T.A., Wong, K.H., Warrior, N.A.: Characterisation of carbon fibres recycled from carbon fibre/epoxy resin composites using supercritical n-propanol. Compos. Sci. Technol. 69, 192-198 (2009)

16. Okajima, I., Hiramatsu, M., Shimamura, Y., Awaya, T., Sako, T.: Chemical recycling of carbon fibers reinforced plastic using supercritical methanol. J. Supercrit. Fluids 91, 68-76 (2014)

17. Liu, Y., Jiang, Z., Tang, T.: Chemical recycling of carbon fibers reinforced epoxy resin composites in subcritical water : synergistic effect of phenol and $\mathrm{KOH}$ on the decomposition efficiency. Polym. Degrad. Stabil. 97, 214-220 (2012)

18. Pinero-Hernanz, R.: Chemical recycling of carbon fibre composites using alcohols under subcritical and supercritical conditions. J. Supercrit. Fluids 46, 83-92 (2008)

19. Jiang, G., Pickering, S.J.: Stucture-property relationship of recycled carbon fibers revealed by pyrolysis recycling process. J. Mater. Sci. 51, 1949-1958 (2016)

20. Ghaemy, M., Mossadegh, K.: Depolymerisation of poly(ethylene terephthalate) fibre wastes using ethylene glycol. Polym. Degrad. Stabil. 90, 570-576 (2005)

21. Yildirir, E., Onwudili Jude, A., Williams Paul, T.: Recovery of carbon fibres and production of high quality fuel gas from the chemical recycling of carbon fibre reinforced plastic wastes. J. Supercrit. Fluids 92, 107-114 (2014)

22. Oliveux, G., Dandy, L.O., Leeke, G.A.: Degradation of a model epoxy resin by solvolysis routes. Polym. Degard. Stabil. 118, 96-103 (2015)

23. Oliveux, G., Dandy, L.O., Leeke, G.A.: Current status of recycling of fibre reinforced polymers: review of technologies, reuse and resulting properties. Prog. Mater. Sci. 72, 61-99 (2015)

24. Patil, D.B., Madhamshettiwar, S.V.: Kinetics and thermodynamic studies of depolymerization of nylon waste by hydrolysis reaction. J. Appl. Chem. 1-8 (2014)

25. Kamimura, A., Kaiso, K., Suzuki, S., Oishi, Y., Ohara, Y., Sugimoto, T., Kasiwagi, K., Yoshimoto, M.: Direct conversion of polyamides to $\omega$-hydroxyalcanoic acid derivatives by using supercritical MeOH. Green Chem. 13, 2055 (2011)

26. Goto, M., Sasaki, M., Hirose, T.: Reactions of polymers in supercritical fluids for chemical recycling of waste plastics. J. Mater. Sci. 41, 1509-1515 (2008)

27. Iwaya, T., Sasaki, M., Goto, M.: Kinetic analysis for hydrothermal depolymerization of nylon 6. Polym. Degrad. Stab. 91, 1989-1995 (2006)

28. Kaweetirawatt, T., Yamaguchi, T., Hayashiyama, S., Sumimoto, M., Kamimura, A., Hori, K.: Nylon 6 depolymerization in supercritical alcohols studied by the QM/MC/FEP method. RSC Adv. 2, 8402-8409 (2012)

29. Kamimura, A., Oishi, Y., Kaiso, K., Sumimoto, M., Sugimoto, T., Kashiwagi, K.: Supercritical secondary alcohols as useful media to convert polyamide into monomeric lactams. ChemsusChem 1, 82-84 (2008)

30. Wang, W., Meng, L., Huang, Y.: Hydrolytic degradation of monomer casting nylon in subcritical water. Polym. Degard. Stabil. 110, 312-317 (2014)

31. Kamimura, A., Ikeda, K., Suzuki, S., Kato, K., Sugimoto, T., Kasiwagi, K., Kaiso, K., Matsumoto, H., Yoshimoto, M.: Efficient conversion of polyamides to $\omega$-hydroxyalcanoic acids: a new method for chemical recycling of waste plastics. ChemSusChem. 7, 2473-2477 (2014)

32. Chaabani, C., Weiss-Hortala, E., Soudais, Y., Barna, R.: Resin removal from carbon-based composites by wet thermochemical process. 5th International Conference on Engineering for Waste and Biomass Valorization. August 25-28 - Rio de Janeiro, Brazil (2014)

33. Weibull, W.: Statistical distributions function of wide applicability. J. Appl. Mech. 18, 293 (1951)

34. Deng, S., Ye L., Yiu-Wing, M., Hong-Yuan L.: Evaluation of fibre tensile strength and fibre/ matrix adhesion using single fibre fragmentation tests. Compos. Part A-Appl. 29, 423-434 (1998)

35. DUPUPET, G.: Fibres de carbone. Technique de l'ingénieur. 4, (2008)

36. Zhang, J.: Different surface treatments of carbon fibers and their influence on the interfacial properties of carbon fibers/epoxy composites. Materials. Ecole Centrale Paris, 19 (2012).

37. Kruse, A., Dinjus, E.: Hot compressed water as reaction medium and reactant properties and synthesis reactions. J. Supercrit. Fluids 39, 362-380 (2007)

38. Sinag, A., Kruse, A., Schwarzkopf, V.: Key compounds of the hydropyrolysis of glucose in supercritical water in the presence of $\mathrm{K}_{2} \mathrm{CO}_{3}$. Ind. Eng. Chem. Res. 42, 3516-3521 (2003)

39. Iwaya, T., Sasaki, M., Goto, M.: Kinetic analysis for hydrothermal depolymerization of nylon 6. Polym. Degrad. Stabil. 91, 1989-1995 (2006)

40. Levchik, S.V., Weil, E.D, Lewin, M.: Thermal decomposition of aliphatic nylons. Polym. Int. 48, 532-557 (1999)

41. Ritz, J., Fuchs, H., Kieczka, H., Moran, WC.: Ullman's Caprolactam. Encyclopedia of industrial chemistry.

42. Chen, J., Liu, G., Jin, L., Ni, P., Li, Z., He, H., Xu, Y., Zhang, J., Dong, J.: Catalytic hydrothermal depolymerization of nylon 6. J. Anal. Appl. Pyrolysis. 87, 50-55 (2010)

43. Yong, TL-K., Matsumura, Y.: Reaction pathways of phenol and benzene decomposition in supercritical water gasification. J. Jpn. Pet. Inst. 56, 331-343 (2013)

44. Su, K.-H., Lin, J.-H., Lin, C.-C.: Influence of reprocessing on the mechanical properties and structure of polyamide 6. J. Mater. Process. Technol. 192-193, 532-538 (2007)

45. Josefina Lozano-Gonzalez, M.A., Teresa Rodriguez-Hernandez, M.A., Eduardo, A., Gonzales-De Los Santos, A., VillalpandoOlmos, J.: Physical-mechanical properties and morphological study on nylon-6 recycling by injection molding. J. Appl. Polym. Sci. 76, 851-858 (2000)

46. McDonald-Wharry, J.: Carbonization of biomass-derived chars and the thermal reduction of a graphene oxide sample studied using Raman spectroscopy. Carbon 59, 383-405 (2013)

47. Tunistra, F., Koenig, J.L.: Raman spectrum of graphite. J. Chem. Phys. 53, 1126-1130 (1970)

48. Ferrari, A.C., Robertson, J.: Interpretation of Raman spectra of disordered and amorphous carbon. Phys. Rev. B. 61, 14095 (2000)

49. Terrones, H., Mackay, A.L.: The Geometry of hypothetical curved graphite structures. Carbon. 30, 1251 (1992) 
50. Kroto, H.W., Heath, J.R., Obrien, S.C., Curl, R.F., Smalley, R.E.: Buckminsterfullerene. Nature 318, 162-163 (1985)

51. Ijima, S.: Helical microtubules of graphitic carbon. Nature 354, $56(1991)$
52. Ugarte, D.: Curling and closure of graphitic networks under electron-beam irradiation. Nature 359, 707 (1992) 